Вестник ВГУ. Серия: Право

УДК 347.94

DOI https://doi.org/10.17308/vsu.proc.law.2020.3/2979

\title{
ОБ ИСПОЛЬЗОВАНИИ ЭЛЕКТРОННЫХ ДОКАЗАТЕЛЬСТВ В ЦИВИЛИСТИЧЕСКОМ ПРОЦЕССЕ
}

\author{
Е. А. Кочеткова \\ Центральный фблиал Российского государственного \\ университета правосудия (2. Воронеж) \\ Поступила в редакцию 24 июня 2020 г.
}

\begin{abstract}
Аннотация: анализируются проблелные вопросы использования электронных доказательств в иивилистическом процессе. Исследуется понятие электронного докулента, критерии допустилости и достоверности электронных доказательств, выявляются практические проблель использования данных доказательств на основании анализа судебной практики.

Ключевые слова: электронный документ, электронное доказательство, допустилость электронных доказательств, достоверность электронных доказательств, иивилистический прочесс.
\end{abstract}

\begin{abstract}
: the article analyzes the problematic issues of the use of electronic evidence in the civil process. The author explores the concept of electronic document, the criteria of admissibility and reliability of electronic evidence, identify practical problems of the use of evidence based on the analysis of judicial practice.

Key words: electronic document, electronic proof, admissibility of electronic evidence, reliability of electronic evidence, civil law process.
\end{abstract}

При стремительной информатизации различных сфер общественной жизни электронное общение набирает обороты, и электронные доказательства все чаще фигурируют в судах при рассмотрении различных категорий дел. В связи с этим актуализируется проблематика использования электронных доказательств в цивилистическом процессе.

Возможность предъявления электронных документов в качестве доказательств впервые была установлена Инструктивными указаниями Госарбитража СССР от 29 июня 1979 г. № И-1-4 «Об использовании в качестве доказательств по арбитражным делам документов, подготовленных с помощью әлектронно-вычислительной техники» ${ }^{1}$. Закреплялось, что стороны в арбитражном процессе вправе представлять в арбитраж документы, подготовленные с помощью электронно-вычислительной техники. Такие документы, содержащие данные об обстоятельствах, имеющих значение для дела, должны приниматься органами арбитража на общих основаниях в качестве письменных доказательств.

Тем не менее определение электронного документа впервые было дано в Федеральном законе от 27 июля 2006 г. № 149-ФЗ (в ред. от 18.03.2019)

\footnotetext{
${ }^{1}$ Сборник инструктивных указаний Государственного арбитража СССР. 1983.

(C) Кочеткова Е. А., 2020
} 
Гражданское право. Гражданский процесс. Арбитражный процесс

«Об информации, информационных технологиях и о защите информации»². Электронный документ понимается, как документированная информация, представленная в электронной форме, т. е. в виде, пригодном для восприятия человеком с использованием электронных вычислительных машин, а также для передачи по информационно-телекоммуникационным сетям или обработки в информационных системах.

Гражданский кодекс РФ признает возможность заключения договора посредством обмена электронными документами, передаваемыми по каналам связи, которые позволяют достоверно установить, что документ исходит от стороны по договору. В данном случае под электронным документом понимается информация, подготовленная, отправленная, полученная или хранимая с помощью электронных, магнитных, оптических либо аналогичных средств, включая обмен информацией в электронной форме и электронную почту (ст. 434).

С 1 января 2017 г. в некоторые законодательные акты были внесены изменения ${ }^{3}$ о применении электронных документов в судах. С этого момента исковые заявления, ходатайства, жалобы и иные документы могут быть поданы в суд в виде электронного документа. Кроме того, данный закон расширил понятие письменных доказательств, содержащееся в процессуальных кодексах, к которым теперь относятся и документы, полученные через Интернет, а также документы, подписанные электронной подписью.

C точки зрения процессуальных норм термин «электронное доказательство» можно трактовать, как один из видов письменных доказательств, который представлен непосредственно в виде электронного документа, информации из сети «Интернет», сообщения, переданного посредством электронной почты; аудиозаписи и видеозаписи в цифровом формате и другое, т. е. они объединены общим признаком - электронная форма.

Положения об электронных доказательствах упоминаются в нескольких статьях Гражданского процессуального кодекса РФ (далее - ГПК РФ). В соответствии со ст. 71 ГПК РФ сведения, которые необходимы для разрешения дела, могут быть получены из письменных доказательств. К ним относятся документы и материалы, выполненные в том числе в форме цифровой, графической записи, а также документов, подписанных электронной подписью. Похожая норма содержится в ст. 75 Арбитражного процессуального кодекса РФ (далее - АПК РФ). Тем не менее в настоящее время законодательство РФ не содержит определения электронного документа как доказательства, также нет и указания на признаки, кото-

${ }^{2}$ Собр. законодательства Рос. Федерации. 2006. № 31 (ч. 1). Ст. 3448 ; 2019. № 12 . Ст. 1220 .

${ }^{3} \mathrm{O}$ внесении изменений в отдельные законодательные акты Российской Федерации в части применения электронных документов в деятельности органов судебной власти : фредер. закон от 23 июня 2016 г. № 220-ФЗ // Собр. законодательства Рос. Федерации. 2016. № 26 (ч. 1). Ст. 3889. 


\section{Вестник ВГУ. Серия: Право}

рыми он должен обладать для признания его допустимым доказательством и приобщении к материалам дела.

Относительно выделения электронных доказательств в качестве самостоятельной категории в связи со специфическим характером их получения и закрепления в науке существует несколько точек зрения.

Ряд исследователей полагает, что электронные доказательства относятся к уже существующим законодательно закрепленным видам, указывая, что отнесение сведений к письменным, вещественным доказательствам, аудио- или видеозаписи зависит от того, какие из данных, сохраненных в электронной форме, имеют доказательственное значение 4 .

С точки зрения ученых, поддерживающих данную позицию, электронные доказательства относятся к традиционным видам доказательств, поэтому, по их мнению, нет необходимости расширения перечня существующих средств доказывания. Однако при этом нет единого мнения о том, к какому именно виду традиционных доказательств относятся электронные документы.

С данной точкой зрения трудно согласиться, поскольку в настоящее время процессуальное законодательство определяет их в качестве традиционного вида - письменных доказательств, закрепляя лишь электронную форму (ч. 1 ст. 71 ГПК РФ, ч. 3 ст. 75 АПК РФ).

Некоторые ученые в связи с отсутствием письменной формы электронных доказательств полагают, что электронные документы не являются письменными доказательствами в чистом виде, и поэтому относят такие документы к вещественным доказательствам ${ }^{5}$. Не соглашаясь с данной позицией, можно отметить, что разграничение между письменными и вещественными доказательствами проводится не только по форме, но и по содержанию. В письменных доказательствах для дела имеет значение именно информация, содержащаяся в документах, в вещественных - их внешние свойства и признаки.

Существует точка зрения и об отнесении электронных доказательств к средствам установления обстоятельств с не вполне определенным или неопределенным статусом ${ }^{6}$.

Ряд ученых обосновывает позицию о выделении электронных доказательств в отдельный новый вид средств доказывания ${ }^{7}$. Думается, что

${ }^{4}$ См.: Ворожбит С. П. Электронные средства доказывания в гражданском и арбитражном процессе // Рос. юстиция. 2011. № 8. С. 28.

${ }_{5}^{5}$ См.: Вершинин А. П. Электронный документ : правовая форма и доказательство в суде : учеб.-практ. пособие. М., 2000. С. 109 ; Мошков E. A. Понятие электронного документа и его применение в качестве доказательства в гражданском и арбитражном судопроизводстве Российской Федерации // Арбитражный и гражданский процесс. 2016. № 9. С. 31.

${ }^{6}$ См.: Боннер А. Т. Традиционные и нетрадиционные средства доказывания в гражданском и арбитражном процессе. М., 2015. С. 471.

${ }^{7}$ См., например: Кудрявцева A. В. Концепция теории доказывания в свете проблемы единства процесса // Актуальные проблемы права России и стран СНГ. 2006 : материалы VIII Междунар. науч.-практ. конф. Челябинск, 2006 ; Зигу- 
Гражданское право. Гражданский процесс. Арбитражный процесс

отнесение электронных документов и материалов к новому виду доказательств является одним из приоритетных направлений, однако в настоящее время оно недостаточно обосновано, поскольку требует своего теоретического осмысления и законодательного закрепления в процессуальном законодательстве.

Тем не менее, несмотря на то что документы, полученные с помощью электронной связи, законодатель отнес к письменным доказательствам (ч. 1 ст. 71 ГПК РФ, ч. 3 ст. 75 АПК РФ), специфика не позволяет полностью приравнивать их к традиционным документам на бумажном носителе.

Естественно, что свойством, присущим любому доказательству, независимо от формы его представления в суд, является его способность нести в себе информацию, подтверждающую или опровергающую факты, включенные в предмет доказывания по делу. Исходя из этого, доказательства формируют внутреннее убеждение суда относительно определенных обстоятельств дела. В связи с этим электронные файлы являются такими же носителями информации, как и другие, и отличаются лишь своей формой.

Представляемая в суд информация для признания ее доказательством должна обладать определенными качествами (допустимость, достоверность, относимость и достаточность). Поэтому подаваемый в суд электронный документ должен отвечать всем требованиям, предъявляемым законом к любому доказательству. Однако к рассмотрению интересны первые два качества, поскольку именно они отличают от других видов доказательств.

Допустимость определяет соответствие порядка получения доказательств требованиям, установленным законом к процессуальной форме их получения.

Для определения допустимости электронного документа необходимо наличие электронной подписи, как обязательного реквизита, который служит для защиты документа от подделки, позволяет идентифицировать владельца сертификата ключа подписи, а также установить отсутствие искажения информации в электронном документе. Данный реквизит придает электронному документу юридическую силу, при этом наличие электронной подписи в ряде случаев не является обязательным, поскольку основная функция такой подписи - предотвращение незаконного использования третьими лицами данных, содержащихся в документе.

Однако на практике гораздо больше распространена электронная переписка, осуществляемая посредством передачи электронных сообщений без использования электронной подписи, поскольку такое общение более удобно и оперативно. Сообщения, которые не содержат электронную

pa $H$. A. Компьютерная информация как вид доказательств в уголовном процессе России : автореф. дис. ... канд. юрид. наук. Челябинск, 2010 ; Нахова E. А. Проблемы электронных доказательств в цивилистическом процессе // Ленингр. юрид. журнал. 2015. № 4 (42). С. 301-312. 


\section{Вестник ВГУ. Серия: Право}

подпись, не приравниваются к документам на бумажном носителе с собственноручной подписью, а также не имеют статуса электронных документов. В связи с этим возникает необходимость определения допустимости такой переписки для признания ее доказательством по делу.

В гражданской процессуальной литературе выделяют следующие условия допустимости электронных доказательств: необходима проверка способа, с помощью которого оно формировалось, и его надежность, а также каким образом данный документ хранился или передавался, идентифицируется его составитель, проверяется обеспечение целостности информации ${ }^{8}$.

Суды рассматривают электронную переписку, представленную на бумажном носителе (как совокупность электронных сообщений сторон), с учетом положений ч. 1 ст. 71 ГПК РФ, в качестве письменного доказательства - иного документа, полученного посредством электронной или другой связи либо иным, позволяющим установить достоверность документа, способом ${ }^{9}$.

Для использования электронных сообщений в качестве доказательственной базы в суде им нужно придать юридическую силу. Так, суд может признать электронную переписку в качестве доказательства, если она была предусмотрена договором, а также если возможно установить источник и адресата сообщения. В данном случае возникает правовая фикция, которая заключается в том, что отправка сообщений с электронного адреса свидетельствует, что данное лицо само совершило отправку сообщения, пока не будет доказано обратное.

Отношение судов к переписке по электронной почте неоднозначно. В некоторых случаях суды признают ее допустимым доказательством, когда такая переписка предусмотрена договором между сторонами ${ }^{10}$. В других - несмотря на то что соглашением между сторонами не предусмотрена возможность использования электронного документооборота, суды исследуют электронную переписку в совокупности с другими доказательствами, оценивая достоверность представленной переписки при совпа-

${ }^{8}$ См.: Нахова E. A. Проблемы электронных доказательств в цивилистическом процессе // Ленингр. юрид. журнал. 2015. № 4 (42). С. 303 ; Седельникова Д. В.

152 Проблемы применения электронного доказательства в гражданском и арбитражном процессах // Правопорядок : история, теория, практика. 2017. № 2 (13). С. 32.

${ }_{9}$ Апелляционное определение Хабаровского краевого суда от 11 мая 2018 г. по делу № 33-2329/2018. Документ не был опубликован ; Апелляционное определение Московского городского суда от 26 января 2018 г. по делу № 33-3789/2018. Документ не был опубликован. Доступ из справ.-правовой системы «КонсультантПлюс».

${ }^{10}$ См., например: Постановление ФАС Восточно-Сибирского округа от 19 декабря 2012 г. по делу № А33-21250/2011. Документ не был опубликован ; определение Верховного Суда РФ от 2 ноября 2017 г. № 307-ЭС17-16985 по делу № А5618744/2016. Документ не был опубликован ; постановление Арбитражного суда Западно-Сибирского округа от 15 мая 2017 г. № Ф04-943/2017 по делу № А457246/2016. Документ не был опубликован. Доступ из справ.-правовой системы «КонсультантПлюс». 
Гражданское право. Гражданский процесс. Арбитражный процесс

дении ее содержания с другими подтвержденными по делу обстоятельствами ${ }^{11}$.

Кроме того, для решения вопроса о допустимости проводится оценка содержания такой переписки (например, относительно обсуждения существенных условий договора в случае возникновения спора о наличии договорных отношений между сторонами $\left.{ }^{12}\right)$.

Вторая позиция судов представляется более обоснованной, поскольку на современном этапе взаимоотношений между контрагентами электронное общение превалирует над классическим «бумажным», в связи с чем его необходимо исследовать в суде при возникновении споров.

Достоверным является доказательство, которое соответствует объективной действительности. При проверке электронного документа на достоверность, его оценке возникает проблема возможной недостоверности таких доказательств ввиду уязвимости информации в электронном виде и возможности ее изменения со стороны третьих лиц. В связи с этим возникает вопрос о качестве информации, поскольку оценка электронных доказательств имеет свои особенности. Например, для установления подлинности электронного документа необходимы специальные знания. Таким образом, в случаях, когда стороны оспаривают содержание либо сомневаются в подлинности электронного документа, появляется необходимость проведения экспертизы, регулируемой ст. 79 ГПК РФ, заключение которой в данном случае станет основанием достоверности доказательства.

Кроме того, достоверность электронных доказательств нередко оценивается во взаимосвязи с другими доказательствами по делу ${ }^{13}$.

Требование относимости подразумевает возможность доказательства не только соответствовать объективной действительности, но и служить средством установления истины по делу, иметь прямое или косвенное к нему отношение. Электронный документ может стать доказательством в цивилистическом процессе, если он содержит не разнообразные фракты, а только факты, которые имеют отношение к делу, при соблюдении предусмотренных законом правил собирания и хранения информации.

В судах по-разному решается вопрос о представлении электронных источников информации, применяемых в качестве доказательств. В дан-

${ }^{11}$ Постановление Арбитражного суда Западно-Сибирского округа от 19 февраля 2019 г. № Ф04-6439/2018 по делу № А03-7689/2017. Документ не был опубликован. Доступ из справ.-правовой системы «КонсультантПлюс».

${ }^{12}$ Решение Краснофрлотского районного суда г. Хабаровска от 25 декабря 2017 г. № 2-1859/2017. URL: https://krasnoflotsky-hbr.sudrf.ru/modules.php?name=sud_delo\&srv_num=1\&name_op=doc\&number $=45117995 \& d e l o \_i d=1540005 \&$ new $=\&$ text number $=1$

${ }^{13}$ Решение Приморского краевого суда от 25 июня 2018 г. по делу № 7-21682/2018. Документ не был опубликован ; постановление Арбитражного суда Волго-Вятского округа от 7 марта 2018 г. № Ф01-6705/2017 по делу N A29-1698/2016. Документ не был опубликован ; Апелляционное определение Верховного суда Республики Саха (Якутия) от 5 февраля 2018 г. по делу № 33-491/2018. Документ не был опубликован. Доступ из справ.-правовой системы «КонсультантПлюс». 


\section{Вестник ВГУ. Серия: Право}

ном случае источник информации нематериален, участники процесса в ходе судебного разбирательства могут представить суду на обозрение такое доказательство с помощью компьютерной техники, либо представить для приобщения к делу его электронные копии, а в материалы дела приобщить распечатки электронных документов, скриншотов электронной переписки.

Суд может сделать такие распечатки самостоятельно, например после осмотра электронных сообщений ${ }^{14}$, либо они представляются лицами, участвующими в деле. В случае просмотра переписки в ходе судебного заседания нередко судьи ограничиваются только осмотром без приобщения распечаток переписки ${ }^{15}$.

Представляется более правильным, что при просмотре в ходе судебного заседания переписки сторон путем входа онлайн на страницы электронной почты участников процесса необходимо подробно описывать в протоколе судебного заседания ход и результаты данного просмотра, а также приобщать к материалам дела распечатку скриншотов просмотренных судом страниц.

Кроме того, в вопросе необходимости заверения представляемой в материалы дела электронной переписки судебная практика разнообразна.

Так, в случае представления суду электронной переписки, заверенной одной из сторон, судом отмечается, что согласно ст. 71 ГПК РФ письменные доказательства представляются в подлиннике или в форме надлежащим образом заверенной копии. В этом случае суд счел, что для правильного разрешения дела необходимо нотариальное удостоверение документа с просмотром электронной почты ${ }^{16}$.

В другом деле ${ }^{17}$ представленные суду электронные письма не были заверены нотариусом, тем не менее суд указал, что данный факт не свидетельствует о недостоверности их содержания, поскольку в ходе судебного заседания судом был произведен просмотр входящих сообщений и вложений к ним, поступивших с адреса электронной почты сторон, и суд исследовал их содержание.

Таким образом, в связи с отсутствием в законодательстве четких требований к форме и порядку предоставления, приобщения к делу и исследования сведений в электронной форме, определения критериев их

${ }^{14}$ Апелляционное определение Пензенского областного суда от 21 мая 2019 г. по делу № 33-1741/2019. Документ не был опубликован. Доступ из справ.-правовой системы «КонсультантПлюс».

${ }^{15}$ Апелляционное определение Ивановского областного суда от 28 марта 2019 г. по делу № 33-472/2019. Документ не был опубликован. Доступ из справ.-правовой системы «КонсультантПлюс».

${ }^{16}$ Апелляционное определение Санкт-Петербургского городского суда от 2 декабря 2014 г. № 33-19549/2014 по делу № 2-5342/2014. Документ не был опубликован. Доступ из справ.-правовой системы «КонсультантПлюс».

${ }_{17}$ Апелляционное определение Омского областного суда от 16 мая 2018 г. по делу № 33-2994/2018. Документ не был опубликован. Доступ из справ.-правовой системы «КонсультантПлюс». 


\section{Гражданское право. Гражданский процесс. Арбитражный процесс}

допустимости и достоверности на практике нередко возникают проблемы в использовании такого рода доказательств, а многие вопросы остаются на усмотрение суда.

Поскольку электронные доказательства все чаще используются в цивилистическом процессе, назрела острая необходимость в их надлежащей законодательной регламентации. Определенные требования к принятию электронных доказательств сформировались. Представление электронных доказательств в настоящее время не вызывает особых сложностей, однако требует определенного законодательного регулирования. Определяя место электронных доказательств в системе доказательств, необходимо предусмотреть открытый перечень таких доказательств, критерии определения допустимости и достоверности, возможность использования электронных документов без привязки к материальному носителю.

Центральный фбилиал Российского государственного университета правосудия (г. Воронеж)

Кочеткова E. А., кандидат юридических наук, доцент кафбедры гражданско-правовых дисииплин

E-mail: elena_kochetkova_00@mail.ru
Central Branch of Russian State University of Justice (Voronezh)

Kochetkova E. A., Candidate of Legal Sciences, Associate Professor of the Civil Law Disciplines Department

E-mail: elena_kochetkova_00@mail.ru 